13 Haq IU, Jackson PR, Yeo WW, Ramsay LE. Sheffield risk and treatment table for cholesterol lowering for primary prevention of coronary heart disease. Lancet 1995;346:1467-71.

14 Ramsay LE, Haq IU, Jackson PR, Yeo WW, Pickin DM, Payne JN. Targeting lipid-lowering drug therapy for primary prevention of coronary disease: an updated Sheffield table. Lancet 1996:348*387-8.

15 Haq IU, Ramsay LE, Jackson PR, Wallis EJ. Prediction of coronary risk for primary prevention of coronary heart disease: a comparison of methods. QJ Med 1999;92:379-85.

16 Joint Health Surveys Unit of Social and Community Planning Research and University College London. Scottish health survey. Colchester: University of Essex, 1995 (computer file, 2nd ed). (The Data Archive (distributor), 30 November 1998. SN;3807.)

17 Downs GR, Clearfield M, Weiss S, Whitney E, Shapiro DR, Beere PA, et al. Primary prevention of acute coronary events with lovastatin in men and women with average cholesterol levels: results of AFCAPS/TexCAPS. JAMA 1998;279:1615-22.

18 Standing Medical Advisory Committee. The use of statins. London: Department of Health, 1997. (11061 HCD Aug 97(04).)

19 Collins R, Peto R. Antihypertensive drug therapy: effects on stroke and coronary heart disease. In: Swales JD, ed. Textbook of hypertension. Oxford: Blackwell Scientific, 1992:1156-64
20 Sytkowski PA, D'Agostino RB, Huse DM, Russell MW, Hartz SC. New coronary risk functions for pharmacologically treated hypertensives: the Framingham heart study. Circulation 1997;96(suppl I):437.

21 Joint National Committee on Prevention, Detection, Evaluation and Treatment of High Blood Pressure and the National High Blood Pressure Education Program Coordinating Committee. The sixth report of the Joint National Committee on prevention, detection, evaluation, and treatment of high blood pressure. Arch Intern Med 1998;157: 2413-46.

22 National Cholesterol Education Programme. Second report of the expert panel on detection, evaluation, and treatment of high blood cholesterol in adults (adult treatment panel II). Circulation 1994;89:1333-45.

23 Guidelines Subcommittee. 1999 World Health OrganizationInternational Society of Hypertension guidelines for the management of hypertension. J Hypertens 1999;17:151-83.

24 Haq IU, Ramsay LE, Yeo WW, Jackson PR, Wallis EJ. Is the Framingham risk function valid for northern European populations? A comparison of methods for estimating absolute coronary risk in high risk men. Heart $1999 ; 81: 40-6$

(Accepted 5 November 1999)

\title{
Using the Framingham model to predict heart disease in the United Kingdom: retrospective study
}

\author{
S Ramachandran, J M French, M P J Vanderpump, P Croft, R H Neary
}

Editorial by Jackson

Department of

Clinical

Biochemistry, North

Staffordshire

Hospital, Stoke on

Trent ST4 7PA

S Ramachandran

senior registrar,

chemical pathology

R H Neary

consultant, chemical

pathology

Department of

Epidemiology,

North Staffordshire

Hospital

P Croft

professor

Department of

Statistics, University

of Newcastle,

Newcastle upon

Tyne NE1 7RU

J M French

research associate

Department of

Endocrinology,

Royal Free

Hospital, London

NW3 2QG

M P J Vanderpump

consultant

endocrinologist

Correspondence to:

R H Neary

nearrh@netscape.

net

BMJ 2000;320:676-7
Guidelines on the use of drugs to lower serum concentrations of lipids to prevent coronary heart disease target treatment to patients who have a high absolute risk of the disease. Although a patient's absolute risk of heart disease can be derived using risk tables ${ }^{1}$-for example, the Sheffield table-these are based on the Framingham model which may not be applicable to the population in the United Kingdom. ${ }^{2}$ We aimed to determine whether the Framingham model accurately predicts the risk of coronary heart disease among white men and women in the United Kingdom.

\section{Participants, methods, and results}

A cross section of the population of Whickham, north east England, was enrolled in a study of ischaemic heart disease between 1972 and 1974 and followed up 20 years later. ${ }^{3}$ At baseline, data was collected on body mass index, family history of coronary heart disease, fasting glucose concentrations, and triglyceride concentrations. Standardised WHO questionnaires on chest pain were administered, and the information necessary to complete the Framingham model (age, sex, systolic blood pressure, ratio of total cholesterol to high density lipoprotein cholesterol, presence of left ventricular hypertrophy, presence of diabetes, and smoking habits ${ }^{4}$ ) was also collected, with the exception of concentrations of high density lipoprotein cholesterol for which values of $1.15 \mathrm{mmol} / \mathrm{l}$ were used for men and $1.4 \mathrm{mmol} / \mathrm{l}$ for women. ${ }^{1}$

Altogether, $77(2.8 \%)$ of the 2779 adults initially enrolled were lost to follow up. Of the remaining 2702, a total of 1877 were still alive at follow up, of whom $1802(96 \%)$ participated. A total of 927 participants were excluded from the analysis for one or more of the following reasons: if they had had heart disease at baseline (172), were aged younger than 30 or older than 75 (702) years, or if they had previously been smokers (371); those who had previously been smokers were excluded because the length of time since quitting was unknown.

Evidence of heart disease occurring in those who had died was identified using death certificates, records from postmortem examinations, hospital notes, or the general practitioner's notes. Coronary morbidity was determined in participants by identifying a history of myocardial infarction or angina, evaluating answers to the WHO questionnaire, and by examining the results of repeat electrocardiography which were classed according to the Minnesota Code. The predicted 20 year risk of heart disease was calculated for each participant using baseline measurements and the Framingham model. Participants were ranked in groups according to predicted risk (for example, $0-4.99 \%$, 5-9.99\%, etc), and the percentage of participants in each group who actually had had an event during follow up was determined. Differences between patients with and without heart disease and the goodness of fit between actual and predicted coronary events were tested using the Student's $t$ test and $\chi^{2}$ analysis.

Of the 1700 participants remaining, 529 (31.1\%) had developed heart disease. A higher proportion of men than women had developed heart disease (257/751 (34.3\%) men v 272/949 (28.7\%) women; $\mathrm{P}=0.015$ ), as had a higher proportion of smokers than non-smokers (344/1017 (33.8\%) v 185/683 (27.1\%); $\mathrm{P}=0.003)$; and $8(57 \%)$ of 14 participants with diabetes had developed heart disease. Those participants who had developed heart disease were older (mean age 54.7 years $v 48.1$ years, $\mathrm{P}<.0001$ ), had higher serum cholesterol concentrations $(6.32 \mathrm{mmol} / \mathrm{l} \quad v \quad 6.05$ $\mathrm{mmol} / \mathrm{l}, \mathrm{P}<.0001)$, and higher systolic blood pressure (151.2 mm Hg $v 138.9 \mathrm{~mm} \mathrm{Hg}, \mathrm{P}<0.0001$ ). In terms of the Framingham risk score, those who had developed heart disease had a mean 20 year risk of 30.5\% (95\% confidence interval $29.2 \%$ to $31.8 \%$ ) compared with those who did not (20 year risk $20.5 \%, 19.7 \%$ to $21.4 \%$; 


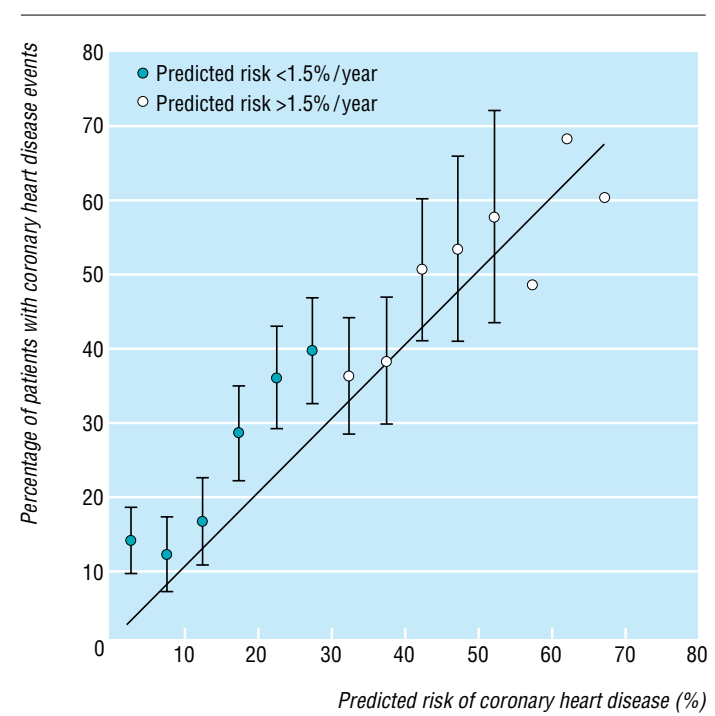

Number of coronary heart disease events observed in the Whickham study compared with number of events predicted by Framingham model in participants with predicted risk below or above $1.5 \% / y e a r$. In the highest risk groups the small number of participants prevents calculation of confidence intervals

$\mathrm{P}<0.0001)$. When individual variables were subjected to logistic regression, male sex, age, blood pressure, smoking status, and cholesterol concentrations were all significant predictors of heart disease but when corrected for the Framingham risk score no single factor remained predictive on its own.

The figure shows the number of coronary events predicted by the Framingham model and the number observed during follow up. The agreement is good at a predicted event rate above $30 \%$ (1.5\% per year), with no significant difference between the observed and expected event rates $(\mathrm{P}=0.85)$. However, at lower event rates the predictive model significantly underestimates the number of observed events $(\mathrm{P}<0.01)$. The wide confidence intervals indicate that there is significant overlap between risk scores in those participants who developed heart disease and those who did not.

\section{Comment}

These results confirm that the Framingham model reliably predicts the absolute risk of heart disease in white men and women in the United Kingdom when the annual risk is above $1.5 \%$, but the model underestimates the risk when the absolute risk is lower. This is consistent with studies that have shown that the model is inaccurate when applied to low risk populations. ${ }^{5} \mathrm{We}$ might have achieved a closer fit with the model by measuring concentrations of high density lipoprotein cholesterol and using a 4 to 12 year follow up period similar to that from which the model was derived. Nevertheless, the recommended threshold for treatment with lipid lowering drugs is based on an annual risk of $3 \%$ per year, ${ }^{1}$ so the Framingham model can be used in clinical practice in the UK population.

We would like to thank Drs M Tunbridge and D Appleton for providing access to the data from the Whickham study and Professor Gilbert MacKenzie for helpful comments on the manuscript.

Contributors: SR and RHN developed the computer database and used it to analyse the data, as suggested by MPJV. MPJV and JMF provided the data. PC provided advice on data analysis and presentation. The paper was written by all of the authors. RHN is guarantor for the study.

Funding: The Department of Health and Newcastle District Research Committee provided financial support for this study.

Competing interests: None declared.

1 Ramsay LE, Haq IU, Jackson PR, Yeo WW, Pickin DM, Payne JN. Targeting lipid-lowering drug therapy for primary prevention of coronary disease: an updated Sheffield table. Lancet 1996;348:387-8.

2 Chambless LE, Dobson AJ, Patterson CC, Raines B. On the use of a logistic score in predicting risk of coronary heart disease. Stat Med 1990;9:385-96

3 Vanderpump MJP, Tunbridge WMG, French JM, Appleton D, Bates D, Clark F, et al. The development of ischemic heart disease in relation to autoimmune thyroid disease in a 20 year follow-up of an English community. Thyroid 1996;6:155-60.

4 Anderson KM, Wilson PWF, Odell PM, Kannel WB. An updated coronary risk profile: a statement for health professionals. Circulation 1991;3:356-62. (American Heart Association statement.)

5 Kannel WB, Larson M. Long-term epidemiologic prediction of coronary disease. Cardiology 1993;82:137-52.

(Accepted 19July 1999)

\title{
Should treatment recommendations for lipid lowering drugs be based on absolute coronary risk or risk reduction?
}

\author{
S Ramachandran, J M French, M P J Vanderpump, P Croft, R H Neary
}

Current guidelines for prescribing lipid lowering drugs are based on an individual's risk of coronary heart disease rather than on the reduction in risk that treatment may bring. We report a strategy for making treatment decisions that combines computer assisted calculation of absolute risk with an estimate of benefit to the patient from treatment.

\section{Subjects, methods, and results}

During a period of 14 months, 17 randomly selected general practices (63 practitioners) in north Stafford- shire were asked to send to the department of clinical biochemistry their requests for coronary heart disease risk assessment on patients being considered for lipid lowering drug treatment.

We used the Framingham statistical model to estimate a patient's absolute risk of coronary heart disease over five years. The reduction in risk that treatment would bring over the next five years was calculated from the product of the absolute five year risk and the risk reduction observed in clinical trials or meta-analysis. The reduction in risk associated with cholesterol lowering drugs was $0.31,{ }^{1}$ which was adjusted
Editorial by Jackson

Department of Clinical

Biochemistry, North Staffordshire Hospital, Stoke on Trent ST4 7PA

S Ramachandran senior registrar, chemical pathology R H Neary consultant, chemical pathology

continued over

BMJ 2000;320:677-9 